\title{
Peritoneal ventilation in rabbits: augmentation of gas exchange with cisapride
}

\author{
J Barr, G Lushkov, S Strauss, S Gurevitch, E Lahat, T Bistritzer, B Klin, G Eshel
}

\begin{abstract}
Background - Peritoneal ventilation has been shown to be effective in achieving extrapulmonary oxygenation and carbon dioxide elimination in an animal model of severe adult respiratory distress syndrome (ARDS). Cisapride is a "prokinetic" agent (increases gastric emptying), that may increase the splanchnic circulation and thus favourably affect gas exchange in peritoneal ventilation.
\end{abstract}

Methods - Using Doppler ultrasound the effect of cisapride on the portal venous circulation was examined in eight spontaneously breathing rabbits and the effect of cisapride on gas exchange in five rabbits spontaneously breathing room air was compared with that of a control group who did not receive cisapride. Its effect on gas exchange in five rabbits with ARDS being treated with mechanical lung and peritoneal ventilation was compared with that of a control group, and its effect on gas exchange in five rabbits with ARDS treated with conventional ventilation was also compared with that of a control group. Results - Enteral administration of cisapride increased portal venous blood velocity, as measured ultrasonographically, by a mean of $188 \%$ one hour after receiving the drug. In rabbits with ARDS being treated with both peritoneal ventilation and mechanical ventilation to the lungs, those receiving cisapride had arterial oxygen tensions 1.5-3 times that of controls. Cisapride had no effect on arterial blood gas tensions in rabbits who were spontaneously breathing room air, nor in rabbits with ARDS who received only conventional mechanical lung ventilation. Conclusions - Cisapride increases arterial oxygenation in rabbits with severe ARDS treated with peritoneal ventilation, probably due to its ability to increase splanchnic circulation. It should be considered as an adjuvant medication to peritoneal ventilation.

(Thorax 1996;51:82-86)

Keywords: peritoneal ventilation, cisapride, ARDS, splanchnic circulation.

"Assaf Harofeh" Medical Center Zerifin 70300, Israel

Reprint requests to: Dr J Barr.

Received 30 January 1995 Returned to authors 30 March 1995 Revised version received 15 May 1995 15 May 1995 ublication 30 August 1995

Persistent intractable hypoxaemia is common in severe adult respiratory distress syndrome (ARDS) treated with conventional mechanical ventilation. There has therefore been an ongoing search for ways of achieving extrapulmonary oxygenation in patients with severe
ARDS which has met with little success. ${ }^{1-9}$ The notable exception has been extracorporeal membrane oxygenation (ECMO), which has shown promising but conflicting results in severe pulmonary disease. Evidence of its benefit in ARDS is inconclusive, ${ }^{1011}$ and it is not always available or technically feasible.

Peritoneal ventilation is theoretically possible because the peritoneum, especially the omentum, has a large, absorptive, highly permeable surface with a rich vascular bed, and is therefore a potential organ for extrapulmonary gas exchange. We have recently described successful peritoneal ventilation through a catheter inserted into the peritoneal cavity of rabbits suffering from ARDS experimentally induced by saline lavage. ${ }^{12}$ The catheter (Argyle Trocar catheter, size $24 \mathrm{Ch}$; Argyle Division of Sherwood Medical, Ireland) was inserted using a procedure similar to that used for insertion of a peritoneal dialysis catheter. Peritoneal ventilation was performed with a Bennet ventilator using time cycled, intermittent mandatory ventilation at a rate of 30 "breaths"/min, peak inspiratory pressure of $8 \mathrm{~cm} \mathrm{H} \mathrm{H}_{2} \mathrm{O}$, positive end expiratory pressure of $2 \mathrm{~cm} \mathrm{H}_{2} \mathrm{O}$, and an inspired oxygen concentration of $100 \%\left(\mathrm{FiO}_{2}\right.$ of $1 \cdot 0)$. When used in addition to conventional mechanical lung ventilation, peritoneal ventilation resulted in significantly better arterial oxygenation and less hypercapnia than controls treated only with mechanical lung ventilation.

Cisapride is a prokinetic agent - that is, it increases gastric emptying. ${ }^{13}$ It is conceivable that, due to the mechanism causing its prokinetic action or as a result of its prokinetic action, it may have an effect on the splanchnic circulation. This might, in turn, have an effect on the properties of the peritoneum as an organ of gas exchange. There is as yet no published work testing these two theories.

The purpose of this present study is therefore twofold; firstly, to test ultrasonographically the influence of cisapride on the splanchnic circulation in spontaneously breathing rabbits, and secondly to investigate the possible role of cisapride in improving gas exchange during peritoneal ventilation in the animal model of ARDS.

\section{Methods}

SUBJECTS

$2 \cdot 5-3 \cdot 5 \mathrm{~kg}$ were studied. All were managed according to the protocols of the National Institutes of Health and the Guiding principles in the care and use of animals of the American Physiological Society. Ethical and methodo- 
logical approval was given by the hospital animal care committee.

STUDY 1

The portal venous blood velocity of eight rabbits was tested by Doppler ultrasound. Food was provided up to six hours before examination and water ad libitum. A crossover study design was used with rabbits randomised to receive either $1 \mathrm{ml}$ normal saline $0.9 \%$ or $1 \mathrm{ml}$ cisapride ( $1 \mathrm{mg} / \mathrm{ml}$ suspension) orally together with diazepam $10 \mathrm{mg}$ intramuscularly for sedation ${ }^{14}$ one hour before the ultrasound examination. The ultrasonographer was unaware of the trial medication given. The medication was crossed over after a 48 hour washout interval and the ultrasound examination repeated as above.

Ultrasound examination was conducted using a $7 \mathrm{MHz}$ sector transducer (Acuson 128, Mountain View, California, USA) with the rabbits supine, being held by an assistant, but not otherwise restrained. The hair in the area examined was shaved to allow good contact between the skin and transducer. The Doppler sample volume cursor was placed at the origin of the portal vein, close to the confluence of the superior mesenteric and splenic veins. The Doppler gate was adjusted to approximately $2-4 \mathrm{~mm}$ and kept in the centre of the vessel. The angle of insonation was calculated automatically by the equipment and kept at $30-60^{\circ}$. Time average velocity (integration of the area under each individual velocity waveform and average of all the mean values in the spectral strip between the two calipers) was calculated from several complete cardiac cycles and represented the mean portal blood velocity.

STUDY 2

Ten rabbits spontaneously breathing room air were studied under mild sedation with intramuscular diazepam $10 \mathrm{mg} .{ }^{14}$ An intravenous infusion ( $15 \mathrm{ml} /$ hour) of saline $0.45 \% /$ glucose $5 \%$ was administered via an ear vein for the duration of the study. An arterial line was inserted in an ear artery (Venflon 22G, Sweden), intermittently flushed with heparinised saline ( 1 unit heparin $/ \mathrm{ml}$ ), and used for sampling arterial blood gas tensions.

The rabbits were randomised into two groups: group A (controls) comprising five rabbits treated with $1 \mathrm{ml}$ doses of oral normal saline, and group B (study group) consisting of five rabbits treated with $1 \mathrm{ml}(1 \mathrm{mg})$ doses of oral cisapride. Each rabbit received a total

Table 1 Mean (SD) arterial blood gas tensions $\left(\mathrm{PaO}_{2}, \mathrm{PaCO}_{2}\right.$, in $\mathrm{kPa}$ ) in rabbits spontaneously breathing room air, who were given either cisapride or placebo

\begin{tabular}{lrrrr}
\hline & 0 min & $60 \mathrm{~min}$ & $120 \mathrm{~min}$ & $180 \mathrm{~min}$ \\
\hline $\mathrm{PaCO}_{2}$ & & & & \\
$\quad$ Control group A & $4.04(0.16)$ & $3.99(0.25)$ & $4.00(0.31)$ & $3.48(0.16)$ \\
$\quad$ Study group B & $4.05(0.15)$ & $3.89(0.41)$ & $4.40(0.37)$ & $3.65(0.23)$ \\
$\mathrm{PaO}_{2}$ & & & & \\
$\quad$ Control group A & $14.21(0.17)$ & $13.01(0.25)$ & $13.07(0.32)$ & $13.15(0.16)$ \\
$\quad$ Study group B & $14.13(0.83)$ & $13.49(0.35)$ & $13.20(0.88)$ & $13.92(1.56)$ \\
\hline
\end{tabular}

Control group $\mathrm{A}=$ five rabbits treated with $1 \mathrm{ml}$ normal saline; study group $\mathrm{B}=$ five rabbits treated with $1 \mathrm{ml}(1 \mathrm{mg})$ cisapride. of three doses of either saline or cisapride administered at 0,60 , and 120 minutes. Arterial blood gas tensions were measured at 0,60 , 120 , and 180 minutes.

\section{STUDY 3}

Ten rabbits were anaesthetised with ketamine/ xylazine. ${ }^{1516}$ An intravenous infusion and an arterial line were set up as in study 2 . The arterial line was used for measuring arterial blood gas tensions and intermittent systolic blood pressure $\left(\mathrm{cm} \mathrm{H}_{2} \mathrm{O}\right)$ using a saline column.

The rabbits were intubated with a size 3.5 endotracheal tube (Portex Ltd, UK). Mechanical ventilation was commenced with a Bennett PR-2 Ventilator (Puritan-Bennett Co, USA) set on IMV (intermittent mandatory ventilation, time cycled, pressure preset) mode, with a respiratory rate of $18 / \mathrm{min}$, PEEP (positive end expiratory pressure) of $2 \mathrm{~cm} \mathrm{H}_{2} \mathrm{O}$, $\mathrm{Pmax}$ (maximum pressure) of $24 \mathrm{~cm} \mathrm{H}_{2} \mathrm{O}, \mathrm{FiO}_{2}$ of $1 \cdot 00$. Each rabbit had a size $7 \cdot 5$ endotracheal tube (Portex Ltd, UK) surgically inserted through a midline incision into the peritoneal cavity with the tip directed towards the right lower quadrant. The peritoneal tube was closed for 15 minutes to allow stabilisation, after which initial arterial blood gas tensions were measured.

ARDS was then induced in each rabbit by saline pulmonary lavage, a technique that we have described and used previously. ${ }^{12}$ This involved disconnecting the rabbit from mechanical ventilation for eight seconds while injecting $20 \mathrm{ml} / \mathrm{kg}$ of normal saline (at $37^{\circ} \mathrm{C}$ ) into the endotracheal tube, after which the tube was reconnected for several breaths. The tube was again disconnected for a period of eight seconds allowing free drainage of saline from the lungs. The whole process was repeated four times in as many minutes, after which the respiratory rate was increased to $44 / \mathrm{min}$ to prevent accumulation of carbon dioxide and respiratory acidosis. No other ventilatory changes were made. Immediately after the lavages, arterial blood gas tensions were measured, peritoneal ventilation was started in addition to the ongoing lung ventilation, and the rabbits received their first dose of either cisapride or a saline control ( 0 minutes).

The peritoneal cavity of the rabbits of both groups was mechanically ventilated using a Bennett PR-2 ventilator, set on IMV mode, at a respiratory rate of 30/min, $\mathrm{Pmax}=8 \mathrm{~cm} \mathrm{H}_{2} \mathrm{O}$, no PEEP, and $\mathrm{FiO}_{2}=1 \cdot 00$.

The rabbits were randomised into two groups: group C (controls) comprising five rabbits given $1 \mathrm{ml}$ normal saline via a nasogastric tube at 0 and 60 minutes, and group D (study group) consisting of five rabbits given $1 \mathrm{ml}$ ( $1 \mathrm{mg}$ ) cisapride via a nasogastric tube at 0 and 60 minutes. Arterial blood gas tensions were measured before lavage and at $0,30,60,90$, and 120 minutes.

STUDY 4

Anaesthesia, vascular access, intravenous infusion, intubation, mechanical ventilation of 
Table 2 Mean (SD) arterial blood gas tensions $\left(\mathrm{PaO}_{2}, \mathrm{PaCO}_{2}\right.$, in kPa) and systolic blood pressure (SBP, in $\left.\mathrm{cm} \mathrm{H}_{2} \mathrm{O}\right)$ in rabbits with ARDS receiving lung and peritoneal ventilation, with and without cisapride

\begin{tabular}{|c|c|c|c|c|c|c|}
\hline & Before lavage & 0 min & $30 \mathrm{~min}$ & $60 \mathrm{~min}$ & $90 \mathrm{~min}$ & $120 \mathrm{~min}$ \\
\hline \multicolumn{7}{|l|}{$\mathrm{PaCO}_{2}$} \\
\hline $\begin{array}{l}\text { Control group C } \\
\text { Study group D }\end{array}$ & $\begin{array}{l}4 \cdot 12(1 \cdot 68) \\
3 \cdot 84(0 \cdot 79)\end{array}$ & $\begin{array}{l}8.91(2.29) \\
8.45(2 \cdot 00)\end{array}$ & $\begin{array}{l}7.09(2.83) \\
5.03(2 \cdot 36)\end{array}$ & $\begin{array}{l}6.23(3.73) \\
5.23(1.83)\end{array}$ & $\begin{array}{l}4.95(2.60) \\
4 \cdot 13(1.64)\end{array}$ & $\begin{array}{l}4.07(1.33) \\
4.77(1.99)\end{array}$ \\
\hline \multicolumn{7}{|l|}{$\mathrm{PaO}_{2}$} \\
\hline $\begin{array}{l}\text { Control group C } \\
\text { Study group D }\end{array}$ & $\begin{array}{l}48.59(5.67) \\
44.03(12 \cdot 7)\end{array}$ & $\begin{array}{l}4.40(1.67) \\
4.69(0.85)\end{array}$ & $\begin{array}{c}9.31(1.04) \\
26.05(9.92)^{*}\end{array}$ & $\begin{array}{l}16 \cdot 29(6 \cdot 17) \\
33.15(7 \cdot 45)^{*}\end{array}$ & $\begin{array}{l}20.88(3.68) \\
36.56(7.07)^{*}\end{array}$ & $\begin{array}{l}24 \cdot 72(3 \cdot 1) \\
34 \cdot 43(5 \cdot 76)^{*}\end{array}$ \\
\hline \multicolumn{7}{|l|}{ SBP } \\
\hline $\begin{array}{l}\text { Control group C } \\
\text { Study group D }\end{array}$ & $\begin{array}{ll}83 \cdot 2 & (19 \cdot 2) \\
75 \cdot 4 & (23 \cdot 7)\end{array}$ & $\begin{array}{ll}87 \cdot 6 & (14 \cdot 7) \\
84 \cdot 0 & (22 \cdot 5)\end{array}$ & $\begin{array}{ll}86 \cdot 0 & (2 \cdot 3) \\
89 \cdot 2 & (15 \cdot 0)\end{array}$ & $\begin{array}{ll}87 \cdot 4 & (6 \cdot 2) \\
83 \cdot 8 & (9 \cdot 3)\end{array}$ & $\begin{array}{ll}85.0 & (10.0) \\
75.6 & (9 \cdot 3)\end{array}$ & $\begin{array}{ll}86.6 & (7 \cdot 06) \\
74.0 & (11.9)\end{array}$ \\
\hline
\end{tabular}

* Comparison between groups reached statistical significance of $\mathrm{p}<0.05$.

Control group $\mathrm{C}=$ five rabbits treated with $1 \mathrm{ml}$ saline at 0 and 60 minutes; study group $\mathrm{D}=$ five rabbits treated with cisapride $1 \mathrm{mg}$ at 0 and 60 minutes.

the lungs, and pulmonary lavage were performed in 10 rabbits as described in study 3 . Ventilatory support was with mechanical lung ventilation alone.

The rabbits were randomised into two groups: group $\mathrm{E}$ (controls) comprising five rabbits treated with $1 \mathrm{ml}$ normal saline via a nasogastric tube at 0 and 60 minutes, and group $\mathrm{F}$ (study group) comprising five rabbits treated with $1 \mathrm{ml}(1 \mathrm{mg})$ cisapride via a nasogastric tube at 0 and 60 minutes. Arterial blood gas tensions were measured before lavage and at 0,30 , and 60 minutes.

\section{STATISTICAL ANALYSIS}

Data were analysed using Statistix Version 3.1 (Analytical Software, USA). Recorded values were compared using analysis of variance and Student's $t$ tests (paired $t$ test for study 1 and the two-sample $t$ test for studies 2-4). A p value of $<0.05$ was considered significant.

\section{Results}

STUDY 1

The ultrasonographic assessment of the portal blood velocity in eight spontaneously breathing rabbits showed that one hour after the oral administration of $1 \mathrm{ml}$ normal saline the mean portal blood velocity was $5 \cdot 5(0.53) \mathrm{cm} / \mathrm{s}$ (range

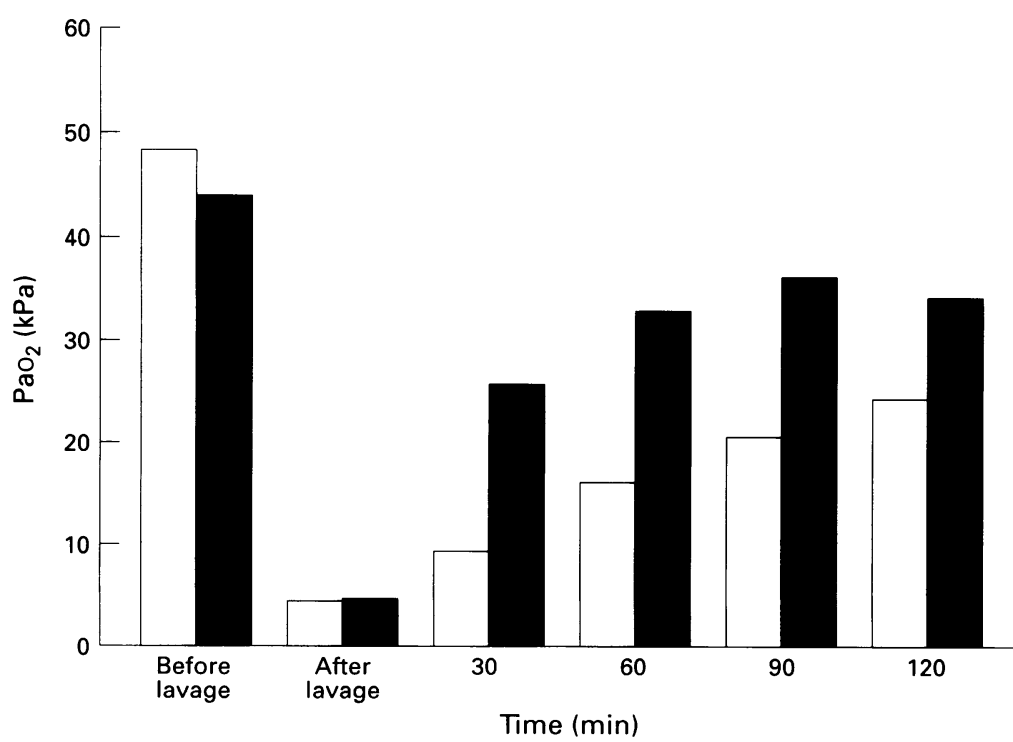

Arterial oxygen tension of rabbits with lavage-induced ARDS on mechanical ventilation (ung and peritoneal, $\mathrm{FiO}_{2}=1 \cdot 00$ ) treated with cisapride (U) or saline ( $\square$ ).
$5-6 \mathrm{~cm} / \mathrm{s})$. One hour after the oral administration of $1 \mathrm{ml}(1 \mathrm{mg})$ cisapride the mean portal blood velocity was $10.38(2 \cdot 2) \mathrm{cm} / \mathrm{s}$ (range $8-14 \mathrm{~cm} / \mathrm{s}$ ), which was significantly higher than after saline administration $(\mathrm{p}<0 \cdot 001)$.

\section{STUDY 2}

We compared the mean arterial oxygen and carbon dioxide tensions $\left(\mathrm{PaO}_{2}, \mathrm{PaCO}_{2}\right)$ of rabbits spontaneously breathing room air in the controls (group A) and cisapride-treated group (group B). No significant differences were seen between the two groups (table 1).

\section{STUDY 3}

We compared the mean $\mathrm{PaO}_{2}, \mathrm{PaCO}_{2}$, and systolic blood pressure in control group $\mathrm{C}$ with the values of study group D (cisapride group). The arterial blood gas tensions and systolic blood pressure were similar in both groups before and immediately after the lavage at 0 minutes. However, at 30,60, 90, and 120 minutes the mean $\mathrm{PaO}_{2}$ values improved by $280 \%, 203 \%, 175 \%$, and $139 \%$, respectively, in group D compared with group $\mathrm{C}(\mathrm{p}<0.05$ for each comparison). There was no significant difference between the two groups in $\mathrm{PaCO}_{2}$ or systolic blood pressure (table 2).

No rabbits died in this study. The $\mathrm{PaO}_{2}$ values recorded are shown in the figure which demonstrates graphically the improvement in arterial oxygenation when oral cisapride is used as an adjunct to peritoneal ventilation.

STUDY 4

There were no significant differences in mean arterial blood gas tensions and systolic blood pressure between the rabbits with ARDS who were treated with either saline or cisapride in addition to conventional lung ventilation (table 3). Four rabbits in each group died within 30 minutes of the lavage. The remaining animal in each group showed marked deterioration in arterial blood gas tensions and systolic blood pressure at 30 minutes and both died 40-45 minutes after the lavage.

\section{Discussion}

ARDS causes significant morbidity and mortality in the intensive care setting, and has no simple therapeutic solution. Various methods 
Table 3 Mean (SD) arterial blood gas tensions $\left(\mathrm{PaO}_{2}, \mathrm{PaCO}_{2}\right.$, in $\mathrm{kPa}$ ) and systolic blood pressures (SBP, in cm $\mathrm{H}_{2} \mathrm{O}$ ) in rabbits with $A R D S$ on conventional lung ventilation, with and without cisapride

\begin{tabular}{|c|c|c|c|c|}
\hline & Before lavage & $0 \min$ & $30 \mathrm{~min}$ & $60 \min$ \\
\hline \multicolumn{5}{|l|}{ No. of rabbits alive } \\
\hline Control group E & 5 & 5 & 1 & 0 \\
\hline Study group $\mathrm{F}$ & 5 & 5 & 1 & 0 \\
\hline \multicolumn{5}{|l|}{$\mathrm{PaCO}_{2}$} \\
\hline Control group E & $3.92(0.19)$ & $5.65(0.52)$ & $7 \cdot 73$ & \\
\hline Study group F & $4.04(0.12)$ & $5 \cdot 25(0 \cdot 29)$ & $8 \cdot 13$ & \\
\hline \multicolumn{5}{|l|}{$\mathrm{PaO}_{2}$} \\
\hline Control group E & $47 \cdot 39(7 \cdot 04)$ & $4.85(1.24)$ & $4 \cdot 13$ & \\
\hline Study group F & $49.04(10.77)$ & $5.09(0.96)$ & $4 \cdot 53$ & \\
\hline \multicolumn{5}{|l|}{ SBP } \\
\hline Control group E & $84 \cdot 2 \quad(11 \cdot 1)$ & $87.5 \quad(14.0)$ & 75 & \\
\hline Study group F & $80 \cdot 0 \quad(7 \cdot 2)$ & $88.1 \quad(6.0)$ & 70 & \\
\hline
\end{tabular}

Control group $\mathrm{E}=$ five rabbits treated with saline at 0 minutes; study group $\mathrm{F}=$ five rabbits treated with $1 \mathrm{mg}$ cisapride at 0 minutes. of mechanical ventilation, including high PEEP and prolonged inspiratory time, have met with little success. ${ }^{12}$ In animals and humans with ARDS different ways of achieving extrapulmonary oxygenation using the vascular system have seemed possible. Although the intravenous infusion of gaseous oxygen gave disappointing results, ${ }^{1-3}$ a breakthrough was achieved with the successful use of ECMO. ${ }^{10}$ The technique, however, has its limitations in that it can only be performed in a few highly specialised centres, it is expensive, requires anticoagulation, cannulation of central vessels, and causes thrombocytopenia, and its efficacy is still in question. ${ }^{11}$ The search has therefore continued for other ways of improving extrapulmonary gas exchange.

The peritoneal cavity, especially the omentum, has a large, absorptive, highly permeable, rich vascular bed, ${ }^{17}$ making it potentially an ideal organ for extrapulmonary gas exchange. The use of peritoneal dialysis using oxygenrich dialysate has given disappointing results, ${ }^{5-9}$ as has continuous insufflation of the peritoneum with oxygen. ${ }^{14}$ This may be explained in part by the fact that most studies were carried out in animals with normal lungs in whom hypoxaemia was induced by lowering the $\mathrm{FiO}_{2}$. Although the oxygen tension in venous blood was often higher than expected in some of these studies, oxygen was then "lost" from the blood to the normal alveoli which had a low alveolar $\mathrm{PO}_{2}$.

We have recently described the successful use of peritoneal ventilation as an adjunct to mechanical lung ventilation in a rabbit model of $\mathrm{ARDS}^{12}$ with significant improvement in hypoxia and hypercapnia over the study period of 120 minutes. The question of whether the improvement would be maintained over a longer period was not investigated. ARDS was induced by five lavages of the rabbit lungs with $20 \mathrm{ml} / \mathrm{kg}$ aliquots of normal saline. The ensuing lung disease is an accepted animal model for human ARDS. ${ }^{18-20}$ Peritoneal and lung ventilation were carried out as described in the methodology of this study. The technique of peritoneal ventilation is simple, inexpensive, does not require equipment more sophisticated than a machine to provide positive pressure ventilation, and in our small study was without complications. Presumably peritoneal vent- ilation would be inappropriate in cases of major abdominal pathology. We assumed that the peritoneal ventilation was successful because of some physical characteristics of the intermittent ventilation itself, given that continuous insufflation of the peritoneum with oxygen has failed in the past. ${ }^{4}$

The aim of our current study was to find a way of further enhancing gas exchange with peritoneal ventilation. Gas exchange depends on many factors, including surface area available for exchange and the perfusion of the surface - the latter seemed amenable to further intervention.

Cisapride is a benzamide that increases gastrointestinal motility and gastric emptying, thus shortening the transit time of compounds passing through the intestine ${ }^{13}$; it is available only as an oral preparation. Its effect on the splanchnic circulation has not specifically been reported, but it does prevent the action of indomethacin in decreasing gastric blood flow and gastric mucosal blood oxygenation in rats, ${ }^{21}$ suggesting that it may increase splanchnic blood flow. If this is true, then it may enhance gas exchange in peritoneal ventilation.

In this study we have shown that cisapride does, indeed, dramatically increase splanchnic blood flow in rabbits, as measured by ultrasound Doppler. We have shown that, in rabbits with ARDS receiving both mechanical lung and peritoneal ventilation, the use of cisapride was associated with a significant improvement in arterial oxygenation but not in carbon dioxide tension. Cisapride had no effect on gas exchange in spontaneously breathing rabbits, nor in rabbits with ARDS treated solely by conventional lung ventilation, hence its beneficial effect must be on some aspect of peritoneal ventilation. Given that the $\mathrm{PCO}_{2}$ did not change significantly, the improved oxygenation with cisapride is presumably due to increased gut perfusion.

We propose that the improved gas exchange seen with cisapride in rabbits with ARDS treated with peritoneal and lung ventilation is due to its observed ability to increase splanchnic circulation. The safety and efficacy of cisapride used with peritoneal ventilation as adjuvant therapy in patients with ARDS who fail conventional treatment deserves further study.

The authors thank Professor George Mundel of Tel Aviv University and former Head of Pediatric Division "Assaf Harofeh" Medical Center for his invaluable review of the manuscript and constructive remarks.

1 Bourne G, Smith RG. The value of intravenous and intraperitoneal administration of oxygen. Am $\mathcal{F}$ Physiol 1927; 82:328-34.

2 Cole F. Intravenous oxygenation. Anesthesia 1951;12:181-8.

3 Singh I, Shah MJ. Intravenous injection of oxygen under

normal atmospheric pressure. Lancet 1940;i:922-3.
4 Awad JA, Brassard A, Caron MW. Intraperitoneal oxygenation. An experimental study in dogs. Int Surg 1970; 53:162-6.

5 Awad JA, Brassard A, Caron WM, Cadrin C. Intraperitoneal oxygenation with hydrogen peroxide. Int Surg 1970;54: oxygena.

6 Klein J, Faithfull NS, Salt PJ, Trouwborst A. Transperitoneal oxygenation with fluorocarbons. Anesth Analg

7 Faithfull NS, Klein J, van der Zee HT, Salt PJ. Whole body oxygenation using intraperitoneal perfusion of fluorocarbons. Br $\mathcal{F}$ Anaesth 1984;56:867-72.

8 Bilge FB, Bedenbaugh PH, von Recum AF. Peritoneal oxygenation. A feasibility analysis. Biomater Artif Cells Artif
Organs 1989;17:413-27. 
9 Siriwardhana SA, Newfield AM, Lipton JM, Giesecke AH. Oxygen delivery by the peritoneal route. Can $\mathcal{F}$ Anaesth 1990;37:S159.

10 Morton A, Dalton H, Kochanek P, Janosky J, Thompson A. Extracorporeal membrane oxygenation for pediatric respiratory failure: five-year experience at the University of Pittsburgh. Crit Care Med 1994;22:1659-67.

11 Morris AH, Wallace CJ, Menlove RL, Clemmer TP, Orme JF, Weaver LK, et al. Randomized clinical trial of pressurecontrolled inverse ratio ventilation and extracorporeal $\mathrm{CO}_{2}$ removal for adult respiratory distress syndrome. $\mathrm{Am}$ Respir Crit Care Med 1994;149:295-305.

12 Barr J, Livne A, Lushkov G, Vinograd I, Efrati Y, Ballin A, et al. Peritoneal ventilation: an animal model of extrapulmonary ventilation in experimental adult respiratory distress syndrome. Pediatr Res 1994;35:682-4.

13 Brunton LL. Agents affecting gastrointestinal water flux and motility, digestants, and bile acids. In: Gilman AG, Rall TW, Nies AS, Taylor P, eds. Goodman and Gilman's The Pharmacological Basis of Therapeutics. 8th edn. New York: Pergamon Press, 1990:928-9.

14 Holmes DD. Clinical laboratory animal medicine. 1st edn Ames, Iowa: Iowa State University Press, 1984:99.
15 White GL, Holmes DD. A comparison of ketamine and the combination ketamine-xylazine for effective surgical anesthesia in the rabbit. Lab Anim Sci 1976;26:804-6.

16 Sanford TD, Colby ED. Effect of xylazine and ketamine on blood pressure, heart rate and respiratory rate in rabbits. Lab Anim Sci 1980;30:519-23.

17 Walker AP, Condon RE. Peritonitis and intraabdominal abscesses. In: Schwartz SI, Shires GT, Spencer FC, eds. Principles of surgery. New York: McGraw-Hill, 1989:145960.

18 Kuckelt W, Dauberschmidt R, Bender V, Hieronymi U, Mrochen $\mathrm{H}$, Winsel $\mathrm{K}$, et al. Experimental investigations in adult respiratory distress syndrome. Repeated pulmonary adult respiratory distress syndrome. Repeated pulmonary

lavage in Lewe-mini-pigs. Exp Pathol 1981;20:88-104.
19 Huber GL, Edmunds LH, Finley TN. Acute effect of saline lung washing on pulmonary mechanics and morphology. Surg Forum 1966;17:113-4.

20 Lachmann B, Robertson B, Vogel J. In-vivo lung lavage as an experimental model of the respiratory distress syndrome. Acta Anaesthesiol Scand 1980;24:231-6.

21 Yokoyama T, Kitazawa T, Ishii A, Ogihara T, Sato N, Karasawa A. Protective effect of cisapride against indomethacin-induced obstruction of the gastric mucosal hemodynamics in rats. $\mathfrak{f p}_{p} \mathcal{f}$ Pharmacol 1994;65:171-3. 